and lecithin chain length (Table II). A detailed model is proposed to account for this behavior.

Received for publication 18 May 1981.

\section{REFERENCES}

1. Burns, R. A., Jr., and M. F. Roberts. 1980. Carbon-13 nuclear resonance studies of short-chain lecithins. Motional and conforma- tional characteristics of micellar and monomeric phospholipid. Biochemistry. 19:3100.

2. Burns, R. A., Jr., M. F. Roberts, R. Dluhy, and R. Mendelsohn. Monomer-to-micelle transition of dihexanoyl phosphatidylcholine: ${ }^{13} \mathrm{C}$ NMR and Raman studies. J. Am. Chem. Soc. In press.

3. Burns, R. A., Jr., Friedmann, and M. F. Roberts. 1981. Characterization of short-chain alkyl ether lecithin analogs: ${ }^{13} \mathrm{C}$ NMR and phospholipase studies. Biochemistry. In press.

4. Burns, R. A., Jr., and M. F. Roberts. 1981. Physical characterization and lipase susceptibility of short chain lecithin/triglyceride mixed micelles: potential lipoprotein models. J. Biol. Chem. 256:2716.

\title{
ASSEMBLY OF THE PROTHROMBINASE COMPLEX
}

\author{
K. G. Mann, M. E. Nesheim, P. B. Tracy, L. S. Hibbard, and J. W. Bloom \\ Hematology Research, Mayo Clinic, Rochester, Minnesota 55901, U.S.A.
}

The term "prothrombinase" refers to the complex composed of the enzyme Factor $\mathrm{X} a$, the cofactor protein Factor $\mathrm{V} a$, calcium ions and phospholipid, which is thought to be responsible for the physiological conversion of the zymogen prothrombin to the enzyme thrombin. Although Factor $\mathrm{X} a$ is sufficient for prothrombin activation, the cofactors increase the rate of thrombin generation $\sim$ 300,000-fold at plasma concentrations of enzyme and substrate. Both the enzyme (Factor $\mathrm{X} a$ ) and the substrate (prothrombin) of this reaction are vitamin K-dependent proteins, each of which possesses $\gamma$-carboxyglutamic acids at the $\mathrm{NH}_{2}$ terminals of their respective peptide chains. As a consequence of these residues, these proteins can, in the presence of calcium, bind membranes containing acidic phospholipids. The cofactor for the reaction, Factor $\mathrm{V} a$, is present in plasma in the form of a "pro" cofactor species, Factor V. Limited proteolysis by thrombin converts the "pro" cofactor, Factor V, to the active cofactor, Factor Va. Current data suggest that Factor $\mathrm{V}$ possesses some minimal level of activity, but that Factor $\mathrm{V} a$ is at least 400 times more active than the uncleaved Factor V.

The "pro" cofactor species, Factor $\mathrm{V}$, is a rather unusual plasma protein. It is a single-chain protein with a molecular weight of 330,000 (1). Both sedimentation and gel filtration analysis of Factor $\mathrm{V}$ suggest that the protein is highly asymmetric. The sedimentation coefficient for Factor $V$ is $\sim 9.2 S$ and the Stokes Radius is $91-93 \AA$ (1, 2). Factor $V$ possesses three binding sites for calcium, two having dissociation constants of $6 \times 10^{-5} \mathrm{M}$, one of $<10^{-8} \mathrm{M}$ (3). This very tightly-bound calcium appears to have structural significance with respect to the ultimate association of Factor $\mathrm{V} a$ polypeptide chains. Thrombin cleaves Factor $\mathrm{V}$ at at least four points in the polypeptide chain, leading to a Factor $\mathrm{V} a$ molecule composed of two to three peptide units. Two peptides with molecular weights of 94,000 and 74,000 are essential for the cofactor activity present in Factor $\mathrm{V} a$ preparations $(3,4)$. A third peptide, with a molecular weight 31,000 , is also associated with the Factor $\mathrm{V} a$ molecule, while two activation peptides with apparent molecular weights 70,000 and 90,000 are not associated with Factor $\mathrm{V} a$. The treatment of Factor $\mathrm{V} a$ with EDTA permits dissociation of the two essential Factor $\mathrm{V} a$ chains $(94,000$ and 74,000$)$, neither of which possesses activity in its own right $(5,6)$. These chains can be reassociated by the readdition of calcium ion. The functions of the remaining polypeptide chains in Factor $\mathrm{V} a$ have not yet been investigated. The Stokes Radius obtained on gel filtration of Factor $\mathrm{V} a$ is $\sim 51 \AA$ (2).

Both Factor $\mathrm{V}$ and Factor $\mathrm{V} a$ bind to phosphatidylcholine-phosphatidylserine vesicles and to blood platelets (7, 8 ). In contrast to the vitamin K-dependent proteins, Factor $\mathrm{V}$ binding to membranes is metal ion and ionic strength independent. The activated cofactor binds to acidic phospholipid-containing vesicles with approximately ten times the affinity of either prothrombin or Factor $\mathrm{X} a$, and binds to a limited number of sites on the platelet membranes with a dissociation constant of $10^{-10} \mathrm{M}$.

\section{RESULTS AND DISCUSSION}

We are examining the participation of each of the three proteins, phospholipid and platelet membranes, and calcium ions in the generation of thrombin from prothrombin. Our approaches include equilibrium binding measurements of each of the species in the reaction system, using light scattering, fluorescence, and sedimentation techniques, and studies of the conversion of prothrombin to thrombin using both a synthetic substrate and prothrombin (9). In the latter case, the fluorescent inhibitor, dansylarginine $N$-(3-ethyl-1,5-pentanediyl)amide (DAPA) has been used as a probe. This compound is a specific inhibitor of thrombin $\left(K_{\mathrm{d}}=4 \times 10^{-8} \mathrm{M}\right)$ and binds reversibly at the active site in 1:1 stoichiometry (10). The bound probe exhibits fluorescence properties allowing for continuous assessment of the formation of thrombin from a zymogen prothrombin.

In addition to equilibrium studies of biomolecular association processes, we have recently extended our stud- 


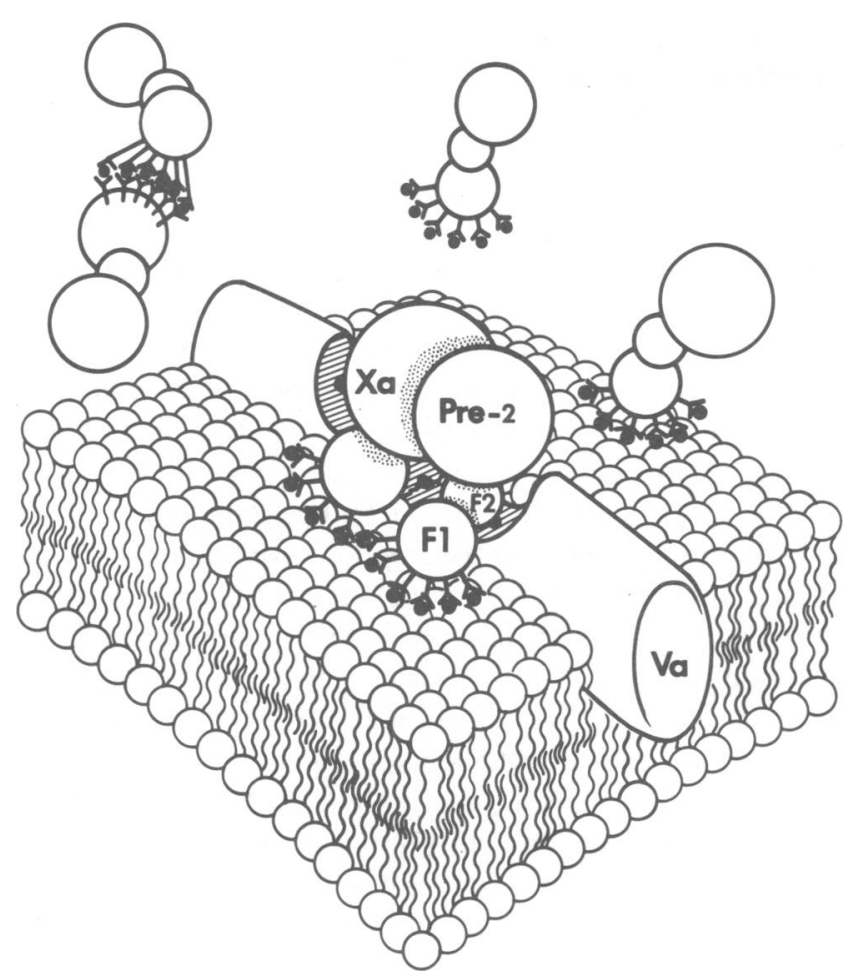

FIGURE 1 Model of the activation of prothrombin as catalyzed by the prothrombinase complex. (From reference 6).

ies to more complex interaction systems, using doubly labeled radioactive probes in studies of platelet binding (11). We have also recently been able to develop (in conjunction with Drs. Elliott Shaw and Charles Kettner) a useful fluorescent Factor $\mathrm{X} a$ derivative which is labeled at the active site histidine with a fluorescent peptide chloromethylketone, dansylglutamylglycylarginine chloromethylketone (12).

The results of studies completed thus far indicate that the substrate (prothrombin) is not an intrinsic component in the formation of the complex catalyst. Factor $\mathrm{V} a$ functions, in part, by partitioning Factor X $a$ to the surface of the phospholipid vesicle or to the platelet membrane surface. Using the composite of kinetic and equilibrium data, we can model the rate enhancement observed for prothrombinase in terms of partitioning of substrate and enzyme to the vesicle surface, enhanced by the catalytic efficiency of Factor Xa.

A model expressing our working hypothesis is presented in Fig. 1. The curved surface denotes a section of a phospholipid vesicle. A molecule of Factor $\mathrm{V} a$ is embedded in the lipid surface and is in 1:1 stoichiometry with Factor $\mathrm{X} a$. Activation of the cofactor through proteolytic cleav- age is suggested by a fissure in the model. Molecules of prothrombin, with the prothrombin fragment-1, prothrombin fragment-2, and prethrombin-2 domains, are shown both in solution and on the vesicle surface. Binding of prothrombin to the phospholipid is suggested through $\mathrm{Ca}^{++}$bridging mediated by the $\gamma$-carboxyglutamate residues of the fragment-1 domain. The interaction of Factor $\mathrm{V} a$ with prothrombin through the fragment- 2 domain is also shown in accordance with inferences drawn previously from studies of prothrombin activation. Prothrombinase is composed of a phospholipid-bound complex of Factor $\mathrm{V} a$ and Factor $\mathrm{X} a$, with $\mathrm{Ca}^{++}$participating in many of the interactions required in the assembly of the catalyst. In this model, Factor $\mathrm{V} a$ provides the "binding site" for Factor $\mathrm{X} a$.

Received for publication 20 April 1981.

\section{REFERENCES}

1. Nesheim, M., K. Myrmel, L. Hibbard, and K. Mann. 1979. Isolation and characterization of single chain bovine Factor V. J. Biol. Chem. 254:308-517.

2. Mann, K. G., M. E. Nesheim, and P. B. Tracy. 1981. The molecular weight of undegraded plasma Factor V. Biochemistry. 20:28-33.

3. Hibbard, L. S., and K. G. Mann. 1980. The calcium binding properties of bovine Factor V. J. Biol. Chem. 255:638-656.

4. Nesheim, M. E., and K. G. Mann. 1979. Thrombin catalyzed activation of a single chain bovine Factor V. J. Biol. Chem. 254:1326-1334.

5. Esmon, C. T. 1979. The subunit structure of thrombin-activated Factor V. J. Biol. Chem. 254:964-973.

6. Nesheim, M. E., L. S. Hibbard, P. B. Tracy, J. W. Bloom, K. H. Myrmel, and K. G. Mann. 1980. Participation of Factor Va in prothrombinase. In The Regulation of Coagulation, Kenneth G. Mann and Fletcher B. Taylor, editors. Elsevier North-Holland, Inc., New York. 145-159.

7. Bloom, J. W., M. E. Nesheim, and K. T. Mann. 1979. Phospholipid binding properties of bovine factor $\mathrm{V}$ and $\mathrm{Va}$. Biochemistry. 18:4419-4425.

8. Tracy, P. B., J. M. Peterson, M. E. Nesheim, F. C. McDuffie, and K. G. Mann. 1979. Interaction of coagulation Factor $\mathrm{V}$ and Factor Va with platelets. J. Biol. Chem. 254:10354-10361.

9. Nesheim, M. E., J. B. Taswell, and K. G. Mann. 1979. The contribution of bovine Factor $\mathrm{V}$ and Factor $\mathrm{V} a$ to the activity of prothrombinase. J. Biol. Chem. 254:10952-10962.

10. Nesheim, M. E., F. G. Prendergast, and K. G. Mann. 1979. Interactions of a fluorescent active-site directed inhibitor of thrombin: dansylarginine N-(3-Ethyl-1,5-pentanediyl)amide. Biochemistry. 18:996-1003.

11. Tracy, P. B., M. E. Nesheim, and K. G. Mann. 1981. Coordinate binding of Factor $\mathrm{V} a$ and Factor $\mathrm{X} a$ to the unstimulated platelet. J. Biol. Chem. 286:743-751.

12. Nesheim, M. E., C. Kettner, E. Shaw, and K. G. Mann. 1981. Fluorescence polarization studies of the assembly of the prothrombinase complex. Fed. Proc. 40:3. 